\title{
A Cognitive Approach to Shakespeare Plays in Immersive Theatre: With a Special Focus on Punchdrunk's Sleep No More in New York (2011-) and Shanghai (2016-)
}

\begin{abstract}
Although cognitive science is an interdisciplinary field, its central questions are 'what is humanity?' and 'what is emotion?' Since the field of theatre and performing arts is deeply concerned with humans and emotions, we expect that it will contribute to the understanding of these concepts. Immersive theatre is an experimental performance form that emphasizes site, space and design while immersing spectators in a play. The number of immersive theatre companies or productions has been growing worldwide. This paper discusses Punchdrunk's Sleep No More, directed by Felix Barrett and performed in London (2003), New York (2011-) and Shanghai (2016-). While elucidating the cognitive impact of immersive Shakespeare performances on spectators, this paper aims to uncover new artistic and cultural value in Shakespeare plays performed in an experimental form in order to advance their contemporary relevance.
\end{abstract}

Keywords: Cognitive science, 4E cognition, immersive theatre, Sleep No More.

\section{Introduction}

Cognitive Approaches to Theatre and Performance Studies

The purpose of this paper is to investigate the phenomenal popularity of Sleep No More, an adaptation of Shakespeare's Macbeth performed by Punchdrunk, one of the most famous international immersive theatre companies, using an emergent cognitive approach. When applicable, this paper refers to the concept of $4 \mathrm{E}$ cognition, which will be explained more in detail below, since it is an insightful and thought-provoking way to explore a work of theatre/performing arts today. Although any work of theatre is a cognitive event, an experimental work, especially in immersive theatre, seems to have greater effects on the audience's 4E cognition. This paper presents not only a cognitive approach to Sleep No More but also the emergent approach through a significant case study, with some suggestions.

* Tokyo Woman's Christian University. 
In the first chapter of The Oxford Handbook of 4E Cognition, the editors discuss the historical roots of the debate between behaviourists and cognitivists regarding key concepts or claims and central issues (Newman et al. 3-15). Addressing the central issue of embodied cognition, they write that there 'is general agreement that a priori definitions or models of cognition are not helpful, and that we need to conduct experiments and consult the empirical literature' (9), and they further admit that they 'are obviously in need of an improved theory of cognition' (13). In her chapter on $4 \mathrm{E}$ cognition and the humanities in the same handbook, Amy Cook reminds us of the true necessity of the 'cognitive turn in the humanities' (890).

Since the concept of $4 \mathrm{E}$ cognition is unstable, as suggested above, it is unlikely that we will obtain a conclusive definition of $4 \mathrm{E}$ cognition at present. Yet, we need a working definition for our investigation. The key concepts or claims of $4 \mathrm{E}$ cognition in the field of cognitive sciences are too complicated to be discussed in this paper, and therefore I would like to introduce a simple set of working definitions. In her chapter on $4 \mathrm{E}$ cognition for directing in The Routledge Companion to Theatre, Performance and Cognitive Science, edited by Rick Kemp and Bruce McConachie, Rhonda Blair gives a brief reminder of the 4E terms:

Embodied: Cognition isn't separable from our physical being, but rather occurs throughout our physical being. One of many proofs of the interconnectedness of these different aspects of cognition is the inseparability of language production, language comprehension and perception of intent in the brain....

Embedded: Cognition depends heavily on off-loading cognitive work and taking advantage of potentials, or affordances, in the environment, for example, the handle on a cup of hot coffee allows us to pick it up, we stand on a chair to reach a high shelf; a fundamental aspect of cognition derives from the individual's interactions with the environment....

Extended: Cognition can be understood as extending beyond the boundaries of the individual to encompass aspects of our material environment as well as our social, interpersonal environment. The ecology in which we live and to which we react includes other people....

Enacted: Cognition is inseparable from action and is an outgrowth and even an attribute of action. A particularly valuable insight for actors is Alva Noë's that perception is 'something we do ... What we perceive is determined by what we do (or what we know how to do); it is determined by what we are ready to do ... we enact our perceptual experience; we act it out'... (91-92)

The concepts of $4 \mathrm{E}$ cognition are not always clear, and they obviously overlap and connect. The point is, however, that they open up a new way of thinking about theatre and performance. 


\section{Immersive Theatre}

Immersive theatre has in all probability existed from ancient times, since most theatre and rituals made audiences participate in the play or event by immersing them in it. ${ }^{1}$ In her book Immersive Theatres: Intimacy and Immediacy in Contemporary Performance, published in 2013, however, Josephine Machon rightly points out a danger that 'immersive' is becoming a catch-all term or an umbrella term 'for any work that occurs outside of the conventional, spectatorial theatre set-up' (66) and concludes:

In brief, the [immersive] event must establish a unique 'in-its-own-world'ness, which is created through a dexterous use of space, scenography, sound, duration within interdisciplinary (or hybridised) practice. Bodies are prioritised in this world; performing and perceiving bodies; the latter belonging to the individuals who make up the audience - a pivotal feature of this practice - whose direct insertion in and interaction with the world shapes the outcomes of the event. (278)

Although the site, environment, bodies and senses are emphasized, this brief summary of immersive theatre reminds us of the importance of $4 \mathrm{E}$ cognition as well. More recently, Stephen M. Eckert says of immersive theatre and its audience's changing desire:

Immersive theater is a performance form emphasizing the importance of space and design; curating tangible, sensual environments; and focusing on personal, individual audience experience. The form has emerged over the past two decades as a major movement in performance and finds itself today within a mainstream moment. As a form which subverts much of the established relationships of conventional theater, its success can be seen as reflecting a larger need in today's audiences. With much of contemporary life taking place in ungrounded, digital spaces, audiences long to exist as physical bodies in actual locations; presented with a culture that is two-dimensional, today's audiences seek expansive, visceral stimuli; within a society lacking privacy, audiences find the prospect of an intimate, personal experience alluring. (1)

Against the background of socio-cultural change and technological developments, certainly, immersive theatre has become mainstream now in the West End, Broadway and many other large cities around the globe, resulting in

${ }^{1}$ It is of great interest that Biggin writes that immersion 'is rooted in the ritual of baptism ... Leaving a state of immersion is a distinct and deliberate as going in. You go in; and you come out, changed' (27). The ritual of baptism as a religious event has a decisive impact on a recipient's embodied cognition. 
a significant change in the relationship between a play and the audience. Immersive theatre gives audience members participatory experiences, since they are invited to join the performance not as passive spectators but as active agents deciding which action or story they will choose from a variety of options and negotiating the process. In other words, immersive theatre is cognitively demanding. However, while living in a digital society where it is growing harder for people to get in contact with the real or the vital due to the digital filter, they want to experience the real or the vital and are attracted to immersive theatre.

Despite its popularity, widespread critical acclaim or attention and commercial success, immersive theatre is controversial for several reasons, ranging from its appreciation or narcissistic exploitation of the audience members' individual experiences to its immediate interaction between performers and the audience, which can collapse the boundary between professional acting and non-professional acting, to neo-liberalist attitudes or its entire absence of political purpose (Alston 11-17, 113-20; Drees 101-105; Gordon 43-50; O’Hara 481-96; Papaioannou 160-74; Prince 255; Purcell 294-95). Although some criticism might be legitimate, immersive theatre gives spectators, digital natives, Instagram narcissists or the like intense cognitive impact. The purpose of this paper is, mainly, not to criticize immersive theatres but to rethink the effects that immersive theatre works have continued to have on spectators' cognition.

Punchdrunk's Sleep No More in New York (2011-) and Shanghai (2016-)

British experimental theatre company Punchdrunk produced the original version of Sleep No More (SNM hereafter), an adaptation of Shakespeare's Macbeth inspired by Hitchcock's films, directed by Felix Barrett and Maxime Doyle and choreographed by Doyle in London in 2003. After having collaborated with Boston's American Repertory Theatre, the company reinvented SNM as an immersive theatre installation in a co-production with EMURSIVE. It began performance at the McKittrick Hotel, which shares a name with the hotel in Hitchcock's movie Vertigo, in Manhattan in 2011. SNM was a phenomenal success and has been performed in New York since 2011. The company began to produce SNM at the McKinnon Hotel in Shanghai in December 2016, and it is still running there. Retaining the main narrative of the New York version, SNM in Shanghai is the reimagined version. As Barrett was keen to attract the Shanghai audience, he worked closely with Chinese performers and designers to make it feel as if it was created and owned by the city. In The Punchdrunk Encyclopaedia, written and prepared by Josephine Machon with Punchdrunk, Machon writes: 
Transposing the world from 1930s Scotland to 1930s Shanghai naturally shifted its aesthetic. While the setting, seeded in Boston, of the colonial hotel remains, new stories traverse six storeys of the McKinnon Hotel. An entirely new subplot, the Chinese legend of 'The White Snake', now serves as the narrative anchor. (260)

Despite this significant difference, both versions of $S N M$ are much the same, as they situate the audience as an epicentre at which all elements of the production converge. Although a cultural difference in audience behaviour between the two cities appears (drinkthehalo), the company's dramaturgy is basically true of its production of $S N M$ in New York and later in Shanghai. SNM's audience members roam about more than 100 rooms of the purpose-built hotel, ranging from the hotel lobby to the chapel, Hecate's Apothecary and the Ballroom, following characters such as Macbeth, Lady Macbeth and Witches or the White Snake, who play or embody some scenes without speech in many rooms. Since the auditorium is not separated from the stage in a proscenium theatre, there is no boundary between the audience and the performers in the site. Wearing masks, spectators participate in the play anonymously or like ghosts. The distance between spectators and performers is close to the extent that the production is involved in haptics between them, bringing out blockbuster one-on-one relationships at times (in English in New York and in Mandarin in Shanghai). Following a different character to learn his or her secrets, each spectator has his or her own experience and weaves his or her own narrative.

Although Punchdrunk seems to enter a post-SNM or post-immersive theatre stage ${ }^{2}$ this paper will examine several elements of the productionverbal/non-verbal semiotic resources, game and attention and memory and loop-by exploring the production's impact on the audience's cognition.

\section{A Wordless Production with Rich Semiotic Resources}

SNM is wordless, with a cast of actors, dancers and dance-trained performers with a physical dramaturgy, apparently prioritizing body and space. Equally significant, in the beginning, Barrett collected fragments of film noir soundtracks and created 'a sonic palette for the show': 'It was an easy leap from film noir to Macbeth' (Interview 21) since the play contains all the classic noir motifs of passion, a femme fatale and a power-obsessed man. As a result,

${ }^{2}$ In a recent interview, Barrett says, 'That crazy space between video games and theatre, I reckon is the next frontier... In the same way as there are 15 different genres of games, we'll soon have 15 different genres of shows. I actually don't think there's a vocabulary for it yet. For a while, "immersive theatre" was bandied about, but whatever this new thing is called, playable shows are the future'(Judge 4). 
although, to be strict, Alfred Hitchcock is not a film noir director, SNM is overwhelmingly influenced by his soundtracks and thriller films, such as Rebecca, Vertigo and Birds. Significantly, Hitchcock loved silent films and did not appreciate talkies, since he wanted to make spectators understand or imagine everything about his film not by characters' words but by brilliant images. The film director's fundamental desire reminds us of Gibson's 'direct perception', 'ecological affordance' (Hamana 91) and embedded cognition in particular. From the start, Shakespeare's play was robbed of its poetic words in SNM, and instead it was reimagined and recreated for a new immersive experiment with highly emotive body language or embodied cognition; obviously, it does not aim at a new critical interpretation of the original play but attempts to produce it in a new way that extends spectators' cognition.

For all its wordless production, $S N M$ is abundant with a variety of unspoken semiotic resources: written or typed messages, letters, newspapers used in set design, costumes (or naked or half-naked bodies), sound and musical design (effects), lighting design, props, acting and dancing. All these resources the spectators can watch in close and intimate spaces, and they have a variety of effects on the audience's cognition. Although SNM seems to be extremely complicated, as it is performed in more than 100 rooms, its synopsis is rather simple: a one-hour version of Macbeth's regicide with a climax of the banquet scene is looped three times with variations for three hours. Although the spectators do not follow the plot linearly, they are led to come together to watch the bloody, mad and queer banquet, performed with a slow-motion cinematic technique as well as other effects, in the underground ballroom at the end of three loops. The spectators are quite busy cognizing what they have watched or are watching.

Both the McKittrick Hotel in New York and the slightly smaller McKinnon Hotel in Shanghai are divided into many rooms, where a variety of actions and installations are performed and presented. There is no strict division between spectators and the play world in an immersive space (or environment or ecology). Once they join the show, the masked spectators keep moving around, up and down, observing the show and installations in their own ways for three hours. This is really a physical theatre for the participants themselves, thrilling with the murders, blood, insomnia, madness and death and going into the darkest depth of human desires and criminal psychology. Understanding each scene, each character and the whole show depends on each spectator. In this uncanny and unusual environment, their cognition does not function like in their ordinary lives. Their cognition is likely to be suspended between the theatrical reality and the theatrical non-reality (mystery), since they are not sure how they understand, know and respond to the situation. It seems hard to explain here exactly how cognition is embodied, embedded, extended and enacted, although their cognition must function actively to take part in the show. Evidently, however, 
this uncanny situation thrills the spectators with wonder. In the borderless space between the spectators and performers, the spectators move freely by their own wills; have extended and intimate relationships with the performers, including one-on-one; and experience the dramatic world with their own bodies. Sharing the same space and event, their ideas could influence each other and at times be blended. An immersive theatre such as SNM moves out of the proscenium stage and comes to have an embodied and extended relationship with the audience in the same flow of time that the body experiences. The spectators also influence the show, and it blends itself with them (extended cognition). The spectators wander into a theatrical world with their own bodies, and the world is changed by their existence. The spectators immerse themselves with other members all together with their bodies and cognition and are going to change the border between the spectators and performers into a borderless and extended relationship. An immersive theatre explores the show's impact on the spectators' cognition.

\section{SNM as a Reimagined Game Version of Macbeth}

It is well-known that Punchdrunk employs game mechanics in its productions. It should be remembered that the stage performance in Shakespeare's age was 'immersive' in its own way, as possibly represented in today's theatres, such as the Globe. When we play Shakespeare games or take part in a gamified Shakespeare performance, we might be having an experience similar to that of Shakespeare's contemporary spectator.

Biggin considers the relationship between an immersive gaming atmosphere and narrative association in the context of adaptation such as SNM; in this case, performers enact narrative events, within a space that has story events embedded within its mise-en-scene and overall design (164). Mentioning game elements in the show, she further writes:

Evoked or enacted narratives reveal themselves as an audience member crosses the space: events in the plot become events in space, which they seek out, stumble upon or enact themselves. An embedded narrative implies a quest or goal that could lead to immersive gameplay experience in an audience member/player.... (164-65) ${ }^{3}$

\footnotetext{
3 An interesting experiment was conducted between Punchdrunk and MIT Media Lab in 2012. It involved turning $S N M$ into a computer game that could be experienced at a distance from the show itself: $S N M$ 'was adapted into a hybrid form of theatre and game' (Biggin 160; Torpey et al.).
} 
In $S N M$, the main events (or narratives) are embedded in the environment and are enacted by the performers. In fact, both the performer's cognition and the spectator's cognition are enacted in the sense that they involve active engagements.

No one seems to have discussed the effect of sustained attention in SNM. While it is rather usual for us to find some audience members asleep in the middle of a play or film, in SNM no spectator falls asleep, although some might be tired. It is hard for spectators to sleep in an immersive theatre, as they are not seated but are walking and engaging in many cognitive and motor sensory activities. This said, it is a great contemporary problem, especially in schools, that many children and students are unable to sustain attention; educators are exploring how to sustain their attention by implementing digital games, interaction and other teaching methods and tools.

Attention is fundamental to learning processes (or cognitive processes). Digital games improve students' attention spans and working memory. The proper functioning of attention is vital because of its involvement in the regulation of thoughts and emotions. Games have features like increasing challenges, rules and involvement of the player in the quest to gain skills or to be 'enskilled' (Bloom 115) and win the game, which require the exercise of cognitive functions, especially working memory, attention and problem-solving capacity.

In $S N M$, the reimagined game version of Macbeth, spectators' attention is sustained, as they have to decide which character they follow, which room they observe and how to solve other 'problems' on the spot. They have little time to waste. It is usually hard for a director and for players to sustain the audience's attention for a long time. When we find SNM to be a gamification of Shakespeare's play, we can understand why it is very popular, especially among younger people of game generations, and why it has continued long-run performances in New York and Shanghai. Employing diverse methods of the game and entertainment industry, ranging from amazing but apparently superficial fun and pleasure to more profound impact on the spectators' cognition, attention and learning, SNM succeeds in maintaining younger audience members' attention, curiosity and exploration for three hours.

One of the most vital elements in creating a computer game is sound design. Sound is a unique feature compared to other designs, such as visual design, since it solely comes out from the display and immerses the player in the space of the game. The sonic effect is so overwhelming that the player is invited to participate in the game in a moment. The sound staff creates the music and sound effects for a game and makes them perform at the right moment for the player to enjoy the game with maximum excitement and thrill.

In creating $S N M$, Barrett first collected film noir soundtracks and then chose Macbeth to adapt since it fit the collected sounds. While SNM employs many elements of game mechanics, sound design is indeed essential, as it 'is the 
central device, closely followed by the installation and costume, that sets the era in a masked show' (Machon, Punchdrunk Encyclopaedia 194). The company employs the device of 'sampling: a collage of sound effects, musical refrains and references to establish the atmosphere and era of the world' (Machon, Punchdrunk Encyclopaedia 244). Machon writes:

For Dobbie [Stephen Dobbie, creative director of the Punchdrunk International], sampling creates a musical environment that is 'defamiliarised' because 'the audience sort of knows it but it's reworked, a blending of upbeat, downbeat, orchestral snatches of era-defining, 1930s pop music, creating, as Barrett puts it, 'an emotional immediacy' ... The sampling technique itself can subvert expectation, creating an aural rug-pull when it suddenly mixes in a jarring musical style, to turn an emotional or narrative corner or to disorient and defamiliarise at moments of high impacts, as illustrated by the 'Witches Rave' in Sleep No More, Boston and NYC. (244)

More importantly, the company has its own concept of sound design called 'soundscore' that controls the loop structure. Soundscore is defined as 'the full aural composition for any Punchdrunk project whatever its format and composite elements, such as music, abstract sound or narration' (Machon, Punchdrunk Encyclopaedia 262). Employing the complicated threefold layering of soundscore, the company has produced unique sound effects in SNM. Dobbie says:

It wasn't soundtrack as background accompaniment but as the overt manipulator of audience. Despite it being abstracted the sound held them back, stifled them, made them nervous, or run to something. What was impactful was the sheer control that came from the sound. (263)

While grabbed by and enveloped in the unforgettably thrilling and uncanny soundscore, including the Hitchcock suite, the audience experiences a strong effect on their embodied cognition and their extended cognition, which will be discussed in the next section.

\section{Memory, Loops and Extended Cognition}

It is vital to consider the original device of the loop structure employed in SNM as one of the keys to its popularity. Machon writes:

A 'loop' defines the unit of time that completes one full narrative cycle to the penultimate sequence before the crescendo ... The loop itself is broken down into twelve scenes for each character, which plot each stage of that character's 
narrative, fluidly resetting itself from scene twelve back to scene one as the cycle plays out ... Multiple loops for all characters will repeat, many intersect, before the final crescendo of the third loop, which leads to the finale ... The duration is typically a fifty-minute loop repeated three times before the finale, creating a three-hour run. (Punchdrunk Encyclopaedia 173)

In $S N M$, a loop formed by multiple mini-loops is the matrix in which all events, narratives, scenes and acts are embedded. However, no spectator can watch all the elements of the matrix that are performed simultaneously in many rooms. Each spectator experiences the show individually; some might be invited to an empty room by a character to have a one-on-one in which he or she might listen to a character's secret or, to their surprise, Rebecca's mystery. Loops are repeated with subtle differences; performers are also trained to improvise appropriately on the spot, if necessary, according to the spectators' response. The spectators are invited or challenged to follow and watch different characters or scenes in the next loop and the third loop, which leads to the finale of the cinematic slow-motion banquet and Macbeth's hanging in the dark and dusty ballroom of the basement floor, with all the performers and the spectators. The finale is a kind of collaborative and collective experience. Although regarding this loop structure of $S N M$, Machon mentions that 'Sam Booth [Punchdrunk performer] identifies a palpable "sense of fatalism" that can be felt through this looping repetition of narrative' (Punchdrunk Encyclopaedia 173), I do not wholly agree with Booth's view. The spectators fully expect from the beginning that the play is destined to have a tragic ending; while having a sense of ending and 'liberation' from the three-hour thrilling show, they look forward to watching how it will end with awe and wonder.

The loop structure of $S N M$ is not only the unit of time but also, seen from computing and technology, a method of control flow. Narratives, history and memory can flow endlessly. In this show, they are bounded in the loop structure, and in this controlled condition, they develop in a variety of ways, having strong effects on the spectators' cognition or producing cognitive feedback loops, as discussed below.

Memory is a fundamental narrative in SNM. We usually think that memory is the encoding storage and retrieval in the human mind of past experiences, having recourse to information theory. However, from a radical cognitive position, Daniel D. Hutto and Erik Myin criticize:

[I]t becomes clear that the 'storage' metaphor is not the only, or even the most, problematic card in the cognitivist deck ... All of the familiar metaphors relating to the way cognitivists talk about the processing of informationcertainly, any that rely on picturing information as some kind of commodity or abstract contentful message-generate equally deep and serious scientific 
mysteries. Such mysteries need dispelling, one way or another-they want explaining or explaining away. (102)

Hutto and Myin thus tackle 'the hard problem of content' (101, 106-112). Bearing this problem in mind, we discuss here the element of memory, metaphoric or not, in SNM. Both Macbeth and Lady Macbeth are tormented by their guilty memories, just as in Shakespeare's play: the former by the murder of Duncan and blood, the murder of Banquo and his ghost and the murder of the 'pregnant' Lady Macduff and the latter by the sight of the regicide and blood. They were unable to sleep, horror-stricken and losing mental health; in fact, Lady Macbeth is driven mad and rambles and sleepwalks through the building in a crazed and guilty manner.

As is well-known, $S N M$ is a show or event in which spectators can immerse themselves and enjoy different individual experiences. Fans appreciate this aspect, although some scholars have criticized it on the grounds of individualism, neoliberalism and commercialism, as mentioned earlier. The critics' discourses are misleading, since an individual experience is not wholly closed. While responding to the site and narrative in their own ways, members of SNM superfan community and Punchdrunk lovers are, in fact, interconnected and interactive online after the show, sharing, exchanging and expanding their experiential layers and cognitive feedback loops between the performers and the spectators and among fans. The accumulated sum of the participants' individual experiences is stored on the website and forms collective memory-one common experience. The audiences in New York and Shanghai not only enjoy $S N M$ individually but also share their responses via digital media. There are SNM fan communities in the USA and China (Lack; Qian; Ritter 59-77), and the fans as the post-Internet generation contribute to creating collective feedback loops using digital preservation and web archiving technologies. While on the one hand this creates stronger individualism and isolation, on the other, young people tend to be connected by digital means, sharing something in common, even if it is a virtual reality or illusion of collective memory.

Regarding the relationship between feedback loops, which are causeand-effect processes within organisms and systems, and extended cognition, I would like to mention Olga Markič's paper, 'Extended Cognition: Feedback Loops and Coupled Systems'. While discussing two main obstacles threatening the extended cognition hypothesis, causal-constitution fallacy and cognitive bloat, Markič supports a complementary view:

The most important feature of cognitive system being genuinely extended is ... continuous reciprocal causation ... We have to bear in mind that the system is individuated on the bases of the process one is interested in and would be intuitively called cognitive. Such system will be called extended, if the task will 
be accomplished on the basis of continuous mutual interactions between the agent and his artifact ... In a way, analogous processes happen in the brain where there are different feedback loops between different neural components. (277)

Discussing the most common objections to active externalism and the extended mind, she suggests that 'there are better criteria ... namely continuous reciprocal causation and ongoing feedback loops' (277). She thinks that the extended cognition hypothesis 'opens up the need for new interdisciplinary collaborations between biological, humanistic, social and technical approaches' (277); she mentions a good example of investigating 'the role of language as a tool of extending cognition' (278). I would like to add that it will be useful to investigate the role of theatre/performing arts as a tool of extending cognition, since a play performed in an immersive theatre, such as $S N M$, is produced by continuous feedback loops.

\section{Conclusion}

While contemporary cognitive sciences, including $4 \mathrm{E}$ cognition, have been developing or even flourishing, basic concepts themselves have been unstable amid controversies, experiments and research. Although this paper has attempted a cognitive approach to a popular adapted play of Shakespeare's Macbeth in immersive theatre, its outcome is limited, leaving several issues to future development of cognitive approaches to theatre and performing arts. Yet, as this paper has suggested, considering the question of cognition in Shakespeare performances in immersive theatre such as $S N M$ is vital. Both theatre people and audiences tend to be concerned with senses, but they also should reconsider the function of cognition.

It is irrelevant to try to find any fixed interpretation or meaning in $S N M$, which has a strong affinity with computer games, as conventional theatre scholarship and criticism have been trying to do. Both performers and spectators, who might at times be co-performers, do not hope to explore a new interpretation or meaning of this play but to explore some exciting experience or try to solve mysteries. Furthermore, they find it pleasurable to re-construct or re-imagine their own narrative (loop) out of fragmented characters and scenes; their work can be both entertaining and intellectual. When we consider cognitive approaches and 4E cognition, we must liberate ourselves from conventional theatre criticism and literary critical discourses; otherwise, we cannot comprehend what event is occurring or presenting itself on the spot. To put it simply, the historically accumulated meanings or interpretations of the original text of Macbeth do not matter much. What matters most is to understand or, 
better, experience how Punchdrunk presents the visceral desire in the original text in our age and how performers and audience experience the show. We should be reminded that today's audience wants to play the show by means of their cognition, which awaits further exploration. ${ }^{4}$

\section{WORKS CITED}

Alston, Adam. Beyond Immersive Theatre. Palgrave, 2016.

Barret, Felix, and Maxine Doyle. "An Interview with Felix Barrett and Maxine Doyle." Punchdrunk's Sleep No More Program, pp. 20-29.

Biggin, Rose. Immersive Theatre and Audience Experience: Space, Game and Story in the Work of Punchdrunk. London, UK, Routledge, 2017.

Blair, Rhonda. "8. 4E Cognition for Directing: Thornton Wilder's Our Town and Caryl Churchill's Light Shining in Buchinghamshire." The Routledge Companion to Theatre, Performance and Cognitive Science, edited by Rick Kemp and Bruce McConachie, London, UK, Routledge, 2019, pp.91-99.

Bloom, Gina. "Videogame Shakespeare: Enskilling Audiences through Theater-Making Games." Shakespeare Studies, English Department, University of California Davis, vol. 43, 2015, pp. 114-127.

Bulman, James C., editor. The Oxford Handbook of Shakespeare and Performance. Oxford, UK: Oxford University Press, 2017.

Cook, Amy. "47. 4E Cognition and the Humanities." The Oxford Handbook of $4 E$ Cognition, edited by Albert Newman, Leon De Bruin, and Shaun Gallagher, Oxford, UK, Oxford University Press, 2018, pp. 875-90.

Drees, Danielle. "The Sleeping Spectator: A Sleep Cultures Critique of Punchdrunk's Sleep No More." Performance Research: A Journal of the Performing Arts, vol. 21, no. 1, 2016, pp. 101-105.

Drinkthehalo. "sleep-no-more-shanghai-concluding-thoughts." http://drinkthehalo.tumblr. com/post/155070437523/sleep-no-more-shanghai-concluding-thoughts/

Eckert, Stephen M. "What is Immersive Theater?" https://contemporaryperformance.com/ 2017/12/09/immerisive-theater/

Gordon, Colette. "Pedestrian Shakespeare and Punchdrunk's Immersive Theatre." Cahiers Élisabéthains, vol. 82, 2012, pp. 43-50.

Hamana, Emi. "Translingual Performance of King Lear: Lear Dreaming as a Case Study." Litteraria Pragensia: Studies in Literature and Culture, vol. 26, no. 52, 2016, pp. 90-105.

Hutto, Daniel D., and Erik Myin. "5. Going Radical." The Oxford Handbook of $4 E$ Cognition, edited by Albert Newman, Leon De Bruin, and Shaun Gallagher, Oxford, UK, Oxford University Press, 2018, pp. 95-115.

Judge, Alysia. 'Interview: 'Playable Shows Are the Future': What Punchdrunk Theatre Learned from Games." The Guardian. 8 Feb. 2019. https://www.theguardian.

4 This paper was written before the COVID-19 pandemic and the unfortunate closure of theatres around the world. 
com/games/2019/feb/08/playable-shows-are-the-future-what-punchdrunk-theatrelearned-from-video-games

Kemp, Rick, and Bruce McConachie. The Routledge Companion to Theatre, Performance and Cognitive Science. London, UK, Routledge, 2018.

Lack, Hannah. "How a British Theatre Company Found a Tribe of Superfans in China." AnOther. https://www.anothermag.com/. Accessed 14 December 2018.

Machon, Josephine. Immersive Theatres: Intimacy and Immediacy in Contemporary Performance. London, UK, Palgrave Macmillan, 2013.

—, editor. The Punchdrunk Encyclopaedia. London, UK, Routledge, 2018.

Markič, Olga. "Extended Cognition: Feedback Loops and Coupled Systems." Interdisciplinary Description of Complex Systems, vol. 15, no. 4, 2017, pp. 270-280.

Newman, Albert, Leon De Bruin, and Shaun Gallagher, editors. The Oxford Handbook of 4E Cognition. Oxford, UK, Oxford University Press, 2018.

O’Hara, Meghan. "Experience Economics: Immersion, Disposability, and Punchdrunk Theatre." Contemporary Theatre Review, vol. 27, no. 4, 2017, pp. 481-96.

Papaioannou, Spyros. "Immersion, 'Smooth' Spaces and Critical Voyeurism in the Work of Punchdrunk." Studies in Theatre and Performance, vol. 34, no. 2, 2014, pp. 160-74.

Prince, Kathryn. "15. Intimate Epic Macbeths in Contemporary Performance." The Oxford Handbook of Shakespeare and Performance, edited by James C. Bulman, Oxford, UK, Oxford University Press, 2017, pp. 250-63.

Punchdrunk. Sleep No More. New York production. Program.

Purcell, Stephen. "17. 'It's All a Bit of a Risk': Reformulating 'Liveness' in TwentyFirst-Century Performance of Shakespeare." The Oxford Handbook of Shakespeare and Performance, edited by James C. Bulman, Oxford, UK, Oxford University Press, 2017, pp. 284-301.

Qian, Jin. "The Sleep No More Superfan, Explained: As the Immersive Play Hits 500 Shows, We Talk to Its Most Loyal and Biggest Fanatics.” 20 Aug. 2018. http://www.smartshaghai.com/articles/arts/the-sleep-no-more-superfanexplained/

Ritter, Julia M. "Fandom and Punchdrunk's Sleep No More: Audience Ethnography of Immersive Dance." TDR/The Drama Review, vol. 61, no. 4, 2017, pp. 59-77.

Torpey, Peter, Ben Bloomberg, Elena Jessop, and Akito van Troyer. "Remote Theatrical Immersion: Extending Sleep No More." http://opera.media.mit.edu/projects/ sleep_no_more/ 